Portland State University

PDXScholar

6-16-2021

\title{
Corporate Sociopolitical Activism and Nonprofit Identity Orientation on an Individual's Likelihood to Support
}

Tara Duenas

Portland State University

Follow this and additional works at: https://pdxscholar.library.pdx.edu/honorstheses

Part of the Marketing Commons, Nonprofit Administration and Management Commons, and the Organizational Behavior and Theory Commons

Let us know how access to this document benefits you.

\section{Recommended Citation}

Duenas, Tara, "Corporate Sociopolitical Activism and Nonprofit Identity Orientation on an Individual's Likelihood to Support" (2021). University Honors Theses. Paper 1112.

https://doi.org/10.15760/honors.1139

This Thesis is brought to you for free and open access. It has been accepted for inclusion in University Honors Theses by an authorized administrator of PDXScholar. Please contact us if we can make this document more accessible: pdxscholar@pdx.edu. 
Corporate Sociopolitical Activism and Nonprofit Identity Orientation on an Individual's Likelihood to Support

by

Tara Duenas

An undergraduate honors thesis submitted in partial fulfillment of the requirements for the degree of

Bachelor of Science

in

University Honors

and

Marketing and Advertising

Thesis Adviser

Jacob Suher, Ph.D.

Portland State University

2021 


\section{Introduction}

Firms' stakeholders have continually expressed and urged firms to support or take a stance on societal issues like climate change, LGBTQIA+ rights, gender equality, and racial equality. In 2020, police abolition had become a mainstream sociopolitical issue after Ahmaud Arbery, George Floyd, and Breonna Taylor were murdered by the police. However, shareholders or investors of these firms often hold varying/opposing stances on these societal issues thereby firms stay silent or do not take a stance. According to the financial bottom-line theory, investors expect a firm to profit maximize and may be dissuaded by a firm or punish a firm that uses resources to engage in anything other than meeting those expectations (Beck, Bhagwat, et al., 2020). Yet, there have been instances where successful financial consequences occur after a firm has implemented strategies focused on socio-political issues. There have also been economic and reputational backlash to these firms associated to their stance that proposes further exploration.

Due to the increased societal expectation of firms, this has encouraged the development of Corporate Social Responsibility (CSR) and Corporate Political Activity (CPA) frameworks/strategies. CSR and CPA are now incorporated into the daily operations of many firms. These frameworks were specifically created to address stakeholders like customers, employees, and state legislators (to name a few) who can impact a firm's ability to survive. CSR maintains the philosophy to "do well by doing good" which includes doing well economically, philanthropically, and environmentally (Beck, Bhagwat, et al., 2020). CPA addresses federal or state legislators (who can respond more immediately than federal processes) and is a strategy often used, like lobbying, which can ensure economic benefit (Beck, Bhagwat, et al., 2020). Bhagwat, Warren, et al. (2020) define the term of corporate sociopolitical activism (CSA) as a firm's public demonstration of support for or opposition to one side of a partisan sociopolitical issue. In particular, figure 1 illustrates the conceptual distinction between CSA and corporate social responsibility (CSR) and corporate political activity (CPA). Importantly, CSA has been recognized as a marketing strategy that can increase a firm's value in the short-term through metrics observed in the stock market and/or increased sales (Beck, Bhagwat, et al., 2020).

Much of the research that has been conducted on CSA has focused on "mainstream" forprofit corporations. This is a similar story across marketing research where the emphasis of study is on "commercial" marketing (Andreasen, 2012). Therefore, there is a lack of research on nonprofit marketing which could partly be due to the diversity of the nonprofit subsectors and the complexity of operations. Often, nonprofits are analyzed as special cases or one-time scenarios when "commercial" marketing strategies can be applicable and implemented within the nonprofit sector to its potential benefit (Andreasen, 2012). Additionally, there are scholars who argue that nonprofits can benefit greatly by adopting "commercial" marketing orientations, but face barriers of implementation from internal (staff and managers who lack an understanding of benefits) stakeholders (Chad, Kyriazis, et al., 2013). While some nonprofits will overcome internal barriers of implementation for a "commercial" marketing orientation, the "commercial" applications were intentionally designed for the for-profit context which makes the transference of frameworks and tools complicated (Wymer, Boenigk, Möhlmann, 2015). For each nonprofit subsector, it is recognized that when applying a "commercial" marketing orientation it must be adjusted to maximize mission objectives (Wymer, Boenigk, Möhlmann, 2015). With these definitions and theoretical applications provided by research, one can suggest that CSA is a marketing framework that nonprofits can implement and utilize. 
There are different methods of measuring success for nonprofits versus for-profit organizations. Where for-profit firms are financially driven and are measured using financial metrics or key performance indicators. Nonprofits measure for mission centered objectives and outcomes. Sawhill and Williamson wrote an article for the Mckinsey Quarterly where they identified that "every nonprofit organization should measure its progress in fulfilling its mission, its success in mobilizing its resources, and its staff's effectiveness on the job" (Sawhill \& Williamson, 2020). A framework that can be used for measuring performance in any nonprofit is called the "family of measures" and was established by the Nature Conservancy (Sawhill \& Williamson, 2020). While nonprofits are not for-profit, a very vital operation of theirs is to fundraise for their mission, receive contributions, and increase the impact they can have on society. Whether that is being able to finance projects that align with their mission or ensure their staff are compensated fairly. The funding they receive can come from a great variety of stakeholders (Bradley, Jansen, et al., 2003). Grants can come from universities, the government, and public or private firms. Nonprofits can also receive small infrequent one-time donations from individual stakeholders or monthly subscriptions. CSA marketing has the capability of assisting nonprofits to obtain their mission centered objectives, aid in awareness of social movements, and impact societal outcomes. Still little is known on CSA's impact on these objectives therefore there is a gap in the literature regarding CSA and nonprofits.

The two nonprofit organizations that inspired this study are Portland State University (PSU) and SNACK BLOC. Both organizations vary greatly in size and have implemented CSA in response to police abolition within the past year while receiving public funding. Where PSU's acting President released an announcement that campus police will be unarmed by Fall of 2020 (Percy, 2020). There are various organizational differences between these nonprofits but there has been a suggested link in research that an organization's identity orientation influences whether they participate in CSA, specifically corporate activism which is an umbrella term that includes CSA (Eilert \& Cherup, 2020). Eilert \& Cherup (p. 468) identify three types of identity orientations which are individualistic orientation, relational orientation, and collectivistic orientation:

"Companies with a relational orientation perceive themselves as relationship partners and are motivated to engage in activities that provide a benefit to others. Finally, companies with a collectivistic orientation see themselves as members of larger groups or communities and are thus likely to participate in activities focusing on greater collective welfare. We posit that companies with either a relational or collectivistic orientation are motivated and able to engage in successful activism and create change, albeit in different ways and for different reasons."

The purpose of the present study is to investigate whether corporate sociopolitical activism (CSA) as a marketing strategy impacts individual stakeholders and their likelihood to support (time, money, or partnership) a nonprofit who may have different identity orientations (collectivistic or relational). This study will aim to effectively address the following research question: If a nonprofit identifies as relational oriented or collectivistic oriented then utilizes CSA or not, how will that impact the likelihood of individuals/organizations to support them (inkind, monetarily, or for-profit partnership)? A hypothesis is that if a collectivistic oriented nonprofit utilizes CSA then it will increase the likelihood of support (money). An obervation witnessed to test this hypothesis developed from SNACK BLOC, a collectivistic orientation, who conducted CSA. Examples of their CSA (in support of police abolition) were emailing Portland city officials, calls to city/state officials, attending virtual city hall meetings to give 
comments and sitting on the steps of the Justice Center to address police brutality (SNACK BLOC; August 2020). SNACK BLOC then received a grant of $\$ 145,000$ (of the total $\$ 193,000$ fundraised in 2020 until October) from the Oregon Health Authority where the "funding was intended to be of service to and support the health of people in Oregon, particularly people diagnosed with or at higher risk for COVID-19 and associated complications due to longstanding social and health inequities, prioritizing tribal communities and communities of color" (SNACK BLOC, 2020).

\section{Methodology}

Before data collection could occur, this experiment required submitting an IRB exemption which included: four different forms on the purpose of the study, a draft of the survey, and two CITI Program approved certificates in 'Social and Behavioral Responsible Conduct of Research' and 'Human Subjects Research (HSR) Group 1: Human Subjects Researcher'. These documents were submitted to the Human Research Protection Program \& Research Integrity department which acts as the Institutional Review Board at Portland State University. This study needed to be approved prior to any survey administration or data collection.

To explore CSA and Nonprofit Identity Orientations on likelihood to support, a survey was created called 'CSA for Nonprofits' (refer to Appendix A). The survey was constructed utilizing a $2 \times 2$ between-subjects experimental design that had been utilized by marketing scholars like White, MacDonnell, et al. (2011) who tested construal level and message framing on consumer efficacy and conservation behaviors. For this study, the experiment manipulated nonprofit identity orientation (collectivistic oriented vs. relational oriented) and CSA use (utilizes CSA vs. does not utilize CSA). After reading a brief scenario (see Appendix A for complete scenario text), study participants rated their likelihood to support the nonprofit organization (in-kind, monetarily, or for-profit partnership). Once the experiment was approved and considered exempt by the IRB, the survey went live February $8^{\text {th }}, 2021$ and ran for 3 weeks.

This survey was administered virtually to PSU students in the School of Business through Qualtrics software. SONA software allowed for these participants to receive extra credit points by completing surveys which were sent via email. The focal outcome variables were the intentions to support a nonprofit organization with in-kind or monetary donations according to the randomized scenario each respondent received (there were four manipulated scenarios). These scenarios were identified as; $\mathrm{CSA}=0$ and PSU $=1$ (Relational oriented nonprofit does not utilize CSA), $\mathrm{CSA}=1$ and $\mathrm{PSU}=1$ (Relational oriented nonprofit does utilize CSA), $\mathrm{CSA}=0$ and $\mathrm{PSU}=0$ (Collectivistic oriented nonprofit does not utilize CSA), and CSA $=1$ and PSU $=0$ (Collectivistic oriented nonprofit utilizes CSA). The focal outcome variables were the general likelihood to support the nonprofit organization (1-extremely unlikely to 9-extremely likely). Additionally, likelihood to support was measured as time (1-strongly disagree to 9-strongly agree) and as money (1-strongly disagree to 9-strongly agree). The last focal outcome variable measured can be described as the likelihood to partner with a nonprofit organization if one was a for-profit business owner (1-extremely unlikely to 9-extremely likely). Next, the survey measured covariates, including an individual's previous knowledge of the type of organization (collectivist or relational) ranging from low previous knowledge to high previous knowledge and the likelihood of the individual engaging in political activities like inviting a friend to a political 
organization or event, purchasing a poster or merchandise that endorses a political point of view, donating money to a political organization or candidate, attending a political organizations regular planning meeting, blocking access to a building or public with your body, engaging in a political activity in which you feared for your personal safety, and engaging in sociopolitical activity for police abolition (1-extremely unlikely to 7-extremely likely).

There were 12 variables collected in total. Overall, there were 287 anonymous responses or 3,444 data points. As seen in Appendix A, the participants were all provided definitions of CSA, relational/collectivistic oriented identities, and asked the likelihood to support each scenario (potential for a for-profit partnership and asked about their behaviors/characteristics). This data collected from the 'CSA for Nonprofits' survey was cleaned to conduct a correlation analysis and a MANOVA regressing the four measures of organizational support (i.e., support, time, money, partner) on the experimental conditions and covariates. The first step in data cleaning was to delete any data that was collected by Qualtrics software which did not relate to the survey. For example, StartDate/EndDate/Location/Timing/Organization examples and IP Address. Then eliminating responses that were incomplete including test responses.

Additionally, there were responses that included text from the survey answers and the number (1, not likely). Those answers were replaced with the according number minus the text so that the numerical data became cohesive for analysis. Finally, there was the survey feedback/responses to the control questions which were deleted to conduct the statistical analysis.

Figure 2 reports the MANOVA regression and correlation analysis conducted on the survey data using SPSS Software in partnership with a statistician. This provided clarity to determine statistically significant relationships within the $2 \times 2$ factorial design and the focal outcome variables. Figures 3-6 include clustered bar charts to visualize the four manipulated scenarios and effect on the likelihood to support (in-kind, money, and for-profit partnership).

\section{Results}

Refer to figure 2, within the MANOVA chart there are terms that will be referenced to in the analysis. The CSA* PSU statistical breakdown differentiates each $2 \times 2$ scenario that participants were able to respond to and the focal outcome variables (e.g., Likelihood to support). The results indicating relationships are measured as the estimated mean based on the MANOVA predictive model. $\mathrm{CSA}=0$, which indicates no utilization of $\mathrm{CSA}$ as a marketing tool. $\mathrm{CSA}=1$, indicates utilization of CSA as a marketing tool. PSU $=0$, indicates collectivistic nonprofit identity orientation. PSU $=1$, indicates relational nonprofit identity orientation. Refer to figure 2, when reviewing the MANOVA results for CSA* PSU and the associated estimated Mean, which was determined by the participants responses based on a scale of (1-extremely unlikely, 5neither agree or disagree, and 9-extremely likely). The focal outcome variable of likelihood to support assumed that individuals will contribute time, money, or donations to nonprofits that they are supportive of. This question addresses overall feelings of support for a nonprofit depending on each participant. The first findings in the data addressed the research question: If a nonprofit identifies as relational oriented or collectivistic oriented then utilizes CSA or not, how will that impact the likelihood of individuals to support them (in-kind, monetarily, or for-profit partnership)? A hypothesis made at the beginning of the experiment was that if a collectivistic 
oriented nonprofit utilizes CSA that it will increase the likelihood of in-kind \& monetary donations.

For the "Likelihood to Support" findings in figure 3, a collectivistic oriented nonprofit that utilized CSA had an estimated mean of 5.638 which indicates that participants were more likely to support that scenario in comparison to the relational oriented nonprofit that utilized CSA (estimated mean of 4.929). CSA utilized by a collectivistic oriented nonprofit, however, did not influence participants to become extremely likely to support and maintained that they neither agreed or disagreed to support said scenario. A collectivistic or relational oriented nonprofit that utilized CSA had a greater positive influence on survey participants' likelihood to support than if either nonprofit orientation did not utilize CSA (estimated difference of mean of 0.299). This finding was statistically significant for CSA on likelihood to support ( $\mathrm{p}=0.021)$. Refer to figure 3 , for a visualization of the MANOVA results which indicates that it did not matter if the nonprofit identified as collectivistic oriented or relational oriented, if CSA was utilized in the hypothetical survey scenario then this contributed to an estimated positive main effect on participants' likelihood to support. This evidence suggests that nonprofits (collectivistic oriented or relational oriented) that utilize CSA have the capability of effectivily influencing individuals or organizations and their decisions regarding likelihood to support. This explanation could be related to the observations made with SNACK BLOC and their utilization of CSA (police abolition) where they were able to attain a large amount of donations/in-kind support from individuals and organizations. Xie \& Bagozzi (2014) reference insights and motivations behind people's support for nonprofits, as the "empathy-altruism hypothesis" where people are motivated to help by feelings of empathy for people in need or "negative state relief hypothesis" where support for nonprofits alleviates their own feelings of distress or sadness due to others who are suffering. Based on the "empathy-altruism hypothesis," it is likely that the survey participants felt empathy for BIPOC communities and their losses due to police brutality which became a mainstream sociopolitical issue after George Floyd's murder during an arrest went viral. There is not enough evidence to support this suggestion but it is a legitimate variable that could have contributed to these survey results.

The data revealed that there was significant effects of CSA use and collectivistic nonprofit identity orientation ont the likelihood to support with participants' time. This focal outcome variable was based on the assumption that volunteers at nonprofits show their support by donating their time to assist with activities that contribute to nonprofit mission objectives. Refer to figure 4, the MANOVA results within the CSA * PSU chart, survey participants indicated that they were more likely to support with their time if the randomized scenario involved a collectivistic oriented nonprofit that utilized CSA as a marketing tool (estimated mean of 4.967). The difference between participants' likelihood to support with their time for a relational oriented nonprofit that utilized CSA as a marketing tool was by an estimated mean difference of 0.174. Refer to figure 4, to visualize the positive main effect CSA has on the likelihood to support with time across either nonprofit identity orientation. This is supported by MANOVA regression that determined the statistical significance that CSA has on the likelihood to support with time of $\mathrm{p}=0.004$. It is important to note that there seems to be an influence of CSA (action in support of police abolition) that contributes to survey participants' likelihood to support with their time exclusive of the nonprofit identity orientation type. Yet, in regards to the survey question, overall participants indicated that they do not agree or disagree that the utilization of CSA by either nonprofit identity orientation that they would like to support that 
organization with their time. That encourages other questions to be explored. Does the type of CSA (in support of police abolition) influence these survey participants decision to support with their time? Or does CSA (as a marketing tool, exclusive of the type) influence individuals' decision to support with their time? How would percieved support with their time differ from actual support with their time? Does that change for the type of individual, because this pool of participants were college students in the business school? It is important that there is a continuation of research on determining how individuals are influenced by CSA and the nuance that can impact individuals' decisions because that can expand nonprofit marketing tools and provide positive benefits to society when nonprofit mission objectives are met.

Referring to figure 5, the likelihood to support with money had a variety of different findings compared to the previous focal outcome variables analyzed. The "likelihood to support with my money" focal outcome variable was based on the assumption that individuals show their support for nonprofits by donating their money to provide financial resources to a nonprofit and assist with their mission objectives. What was similar to other findings, was that there was a positive main effect of utilizing CSA for a collectivistic oriented nonprofit on the likelihood to support with money. Overall, the participants' estimated mean for this scenario was 4.447. This finding indirectly aligns with the observation of SNACK BLOC (a collectivistic oriented nonprofit) that utilized CSA (in support of police abolition) and their large donation of $\$ 145,000$ received from the OHA. The main differences between this survey outcome are the type of individual as compared to a government entity that provides the monetary support and is actual support rather than hypothetical support. Additionally, the type of individual or entity which provides support to a nonprofit most likely have different donation behaviors. Although, CSA utilized by a collectivistic oriented nonprofit had the highest likelihood to support with their money (estimated mean of 4.447) this was closely followed by the relational oriented nonprofit that did not utilize CSA to be supported monetarily by survey participants (estimated mean of 3.906). This was an unanticipated finding. There are potential variables that could have impacted this outcome. For example, it is possible that this survey population felt more comfortable contributing financially to a relational oriented nonprofit that did not utilize CSA (not supportive of police abolition) because the resources would be directly used for nonprofit mission objectives versus a perceived sociopolitical agenda. There needs to be more research to understand individual donation behavior to analyze the underlying influences of this particular finding.

The least likely scenario to be supported monetarily was the collectivistic oriented nonprofit that did not utilize CSA, with an estimated mean of 3.610. The data collected cannot provide enough evidence into the potential causes for this outcome, but it is possible that the conflict between a collectivistic oriented nonprofit that does not utilize CSA implies that this nonprofit is neglecting internal and external stakeholders therefore creating a perception of uncertainty. Uncertainty (can be perceived as risk) in the accountability of a nonprofit which has the capability of deterring individuals from donating (Slatten, Guidry, \& Austin, 2011). There is an opportunity here for researchers to explore this gap because nonprofits could utilize this information and explore ways to impact perceived risk for individuals' donation behaviors that could improve the likelihood of an individual to support them with money. Either way, survey particpants were least likely to support with their money in all nonprofit identity orientations and CSA scenarios. This overall low likelihood to support with their money to either nonprofit identity that utilized or did not utilize CSA could be contributed to the larger negative economic impact on households (including college students) during the Covid-19 induced recession. The 
Nonprofit Quarterly released an article on "Nonprofits in Recession: Winners and Losers" that analyzed recession-related giving patterns where American households that donated prior to recessions and had limited means are on a downward trajectory (Dubb, McCambridge, Dantas, 2020). This is not to assume that college students have access to limited means but it can be assumed that they are investing their financial resources towards their educational institutions, have decreased capability to work full-time, and/or have experienced layoffs.

The "likelihood to partner" focal outcome variable was based on the assumption that forprofit organizations would show their support of a nonprofit by setting up a short-term or longterm partnership. An example of this partnership could be a portion of proceeds from for-profit sales that are donated to a nonprofit that identifies as collectivistic or relational and utilizes CSA or does not. Refer to figure 6 , to visualize the positive main effect of collectivistic identity orientation on partnering with a for-profit organization. The data indicated that a collectivistic oriented nonprofit increased the likelihood of participants to partner with a for-profit organization whether they utilized CSA (estimated mean of 4.930) or not (estimated mean of 4.898). It is possible that the perception of a collectivistic nonprofit that takes steps for the greater collective welfare includes their for-profit alliance and would most likely make decisions that would benefit their partner and their own nonprofit. Those seem like potential parameters a for-profit business would make when deciding to partner with a nonprofit. Although, there is no peer-reviewed evidence to support that claim, this brings up another research opportunity where for-profit businesses decision making on developing alliances with nonprofits can be explored for the potential benefit of both parties when it comes to implementing CSR and achieving mission objectives (Álvarez-González, García-Rodríguez, Rey-García, et al, 2017). CSA utilization in this scenario, did not make a significant impact on this population to partner (as a for-profit) with a nonprofit. This was a similar finding across the relational oriented nonprofit that did utilize CSA (estimated mean of 4.307) or did not (estimated mean of 4.341). In figure 2, the MANOVA results indicate that the main effect of relational nonprofit orientation had a significant effect on the likelihood to partner $(\mathrm{p}=0.021)$. This supports the finding that relational oriented nonprofits are less likely to be supported by a for-profit partnership dependent on this survey population's results. Overall, the nonprofit identity orientation or utilization of CSA and lack of CSA did not influence this survey population to either agree or disagree to support a forprofit partnership. It's very likely that the business students who participated in this survey did not have adequate information to describe in detail the for-profit partnership and make the hypothetical decision seem worthwhile. For nonprofits, this is a developing trend in marketing techniques to develop an alliance with a for-profit business that increases their sources of revenue or resources to achieve their mission objectives (Álvarez-González, García-Rodríguez, Rey-García, et al, 2017). It would be beneficial for researchers to continue to fill this particular research gap and develop what marketing frameworks or tools can assist nonprofits to achieve their nonprofit mission objectives to benefit all of the stakeholders involved.

\section{Conclusion}

This study was able to provide insight into CSA and nonprofit identity orientation, and the ways the interaction between these variables influence the focal outcome variables (likelihood to support). At this point, it remains unclear whether utilizing CSA defintively has the capability of assisting nonprofits to increase support from individuals and meet mission objectives. There are other findings that can provide direction for further research. The most significant of all of the insights was the positive main effect that CSA had on likelihood to 
support for all the tested nonprofit scenarios (an estimated mean of 5.638). This evidence suggests that nonprofits (collectivistic or relational oriented) that utilize CSA, as a marketing framework, have the capability of influencing individuals or organizations and their decisions regarding likelihood to support. CSA utilized by a collectivistic oriented nonprofit, however, did not influence particpants to become extremely likely to support and maintained that they neither agreed or disagreed to support said scenario. This finding was followed by the positive main effect of CSA on likelihood to support with time across the nonprofit identity orientations of collectivistic (estimated mean of 4.967) and relational (estimated mean of 4.929).

Referring to figure 5, CSA utilized by a collectivistic oriented nonprofit had the highest predicted level of likelihood to support with their money (estimated mean of 4.447) which was closely followed by the relational oriented nonprofit that did not utilize CSA to be supported monetarily by survey participants (estimated mean of 3.906). Either way, survey particpants were least likely to support with their money in all nonprofit identity orientations and CSA scenarios. This was an unanticipated finding. Refer to figure 6 , to visualize the positive main effect of collectivistic identity orientation on partnering with a for-profit organization. The data indicated that a collectivistic oriented nonprofit increased the likelihood of participants to partner with a for-profit organization whether they utilized CSA (estimated mean of 4.930) or not (estimated mean of 4.898). There are limitations to this research due to the pool of participants being college students and living in a world that has changed rapidly within the past year due to a pandemic and pandemic induced recession.

These insights prompt further questions to be explored by researchers to continue to address the research gap between CSA and nonprofits. Does the type of CSA (in support of police abolition) influence these survey participants decision to support with their time? Or does CSA (as a marketing tool, exclusive of the type) influence individuals' decision to support with their time? How would percieved support with their time differ from actual support with their time? Does that change for the type of individual, because this pool of participants were college students in the business school? Some differences to consider between survey outcomes are the type of individual vs. a government entity that provides the monetary support and is actual support vs. perceived support. Additionally, observing the type of individual or entity which provides support to a nonprofit most likely will have different donation behaviors. It is important that there is a continuation of research on determining how individuals are influenced by CSA and the nuance that can impact individuals' likelihood to support because that can determine which nonprofit marketing tools can be used to provide the nonprofit resources and in turn positive benefits to society as nonprofit mission objectives are met. 


\section{References}

Álvarez-González, L. I., García-Rodríguez, N., Rey-García, M., \& Sanzo-Perez, M. J. (2017, February 20). Business-nonprofit partnerships as a driver of internal marketing in nonprofit organizations. Consequences for nonprofit performance and moderators. BRQ Business Research Quarterly. https://www.sciencedirect.com/science/article/pii/S2340943617300014.

Andreasen, A. (2012). Rethinking the Relationship between Social/Nonprofit Marketing and Commercial Marketing - Alan R. Andreasen, 2012. Retrieved October 26, 2020, from https://journals.sagepub.com/doi/pdf/10.1509/jppm.09.035

Bhagwat, Y., Warren, N. L., Beck, J. T., \& Watson, G. F., IV. (2020). Corporate Sociopolitical Activism and Firm Value. Journal of Marketing 2020, 84(5), 1-21. doi:10.1177/00222242920937000

Bradley, B., Jansen, P., \& Silverman, L. (2014, August 01). The Nonprofit Sector's \$100 Billion Opportunity. Retrieved November 10, 2020, from https://hbr.org/2003/05/the-nonprofitsectors-100-billion-opportunity

Dubb, S., McCambridge, R., Dantas, F., \& Wray, L. R. (2020, May 4). Nonprofits in Recession: Winners and Losers. Non Profit News | Nonprofit Quarterly. https://nonprofitquarterly.org/the-great-recession-nonprofit-winners-and-losers/.

Eilert, M., \& Cherup, A. N. (2020). The Activist Company: Examining a Company's Pursuit of Societal through Corporate Activism Using an Institutional Theoretical Lens. Retrieved October 26, 2020, from https://journals-sagepubcom.proxy.lib.pdx.edu/doi/pdf/10.1177/0743915620947408

Paul Chad, Elias Kyriazis \& Judy Motion (2013) Development of a Market Orientation Research Agenda for the Nonprofit Sector, Journal of Nonprofit \& Public Sector Marketing, 25:1, 1-27, DOI: $\underline{10.1080 / 10495142.2013 .759814}$

Percy, S. (2020, October 27). An update about the Campus Public Safety Office. Portland State University. https://www.pdx.edu/news/update-about-campus-public-safety-office.

Sawhill, J., \& Williamson, D. (2020, August 07). Measuring what matters in nonprofits. Retrieved November 10, 2020, from https://www.mckinsey.com/industries/public-andsocial-sector/our-insights/measuring-what-matters-in-nonprofits

Slatten, L. A. D., Guidry, B. N., \& Austen, W. (2011, June). Accreditation and certification in the non-profit sector ... ResearchGate. https://www.researchgate.net/publication/241732765_Accreditation_and_certification_in_t he_non-profit_sector_Organizational_and_economic_implications. 
SNACK BLOC. (2020). Snackbloc.party. Retrieved November 30, 2020, from https://snackbloc.party/

SNACK BLOC [@snackblocpdx]. (2020, August 30). !!Please read and share!! The time to speak up is now.\#blacklivesmatter \#pdx \#portland \#dismantlewhitesupremacy \#abolishpolice \#policebrutality... [Instagram photograph]. Retrieved from https://www.instagram.com/p/CEgmxSYhpKL/?utm_source=ig_web_copy_link

SNACK BLOC [@ snackblocpdx]. (2020, October 2). Image ID Slides 1-3: SNACK BLOC is honored to receive a grant from the Oregon Health Authority in the amount of $\$ 145,000$ !... [nstagram photograph]. Retrieved from https://www.instagram.com/p/CF2YTNpBVLA/?utm_source=ig_web_copy_link

Walter Wymer, Silke Boenigk \& Mareike Möhlmann (2015) The Conceptualization of Nonprofit Marketing Orientation: A Critical Reflection and Contributions Toward Closing the Practice-Theory Gap, Journal of Nonprofit \& Public Sector Marketing, 27:2, 117134, DOI: $\underline{10.1080 / 10495142.2014 .965078}$

White, K., Macdonnell, R., \& Dahl, D. W. (2011). It's the Mind-Set that Matters: The Role of Construal Level and Message Framing in Influencing Consumer Efficacy and Conservation Behaviors. Journal of Marketing Research, 48(3), 472-485. https://doi.org/10.1509/jmkr.48.3.472

Xie, C., \& Bagozzi, R. P. (2014). The Role of Moral Emotions and Consumer Values and Traits in the Decision to Support Nonprofits. Journal of Nonprofit \& Public Sector Marketing, 26(4), 290-311. https://doi.org/10.1080/10495142.2014.965064 
Figure 1. CSA in relation to CSR and CPA

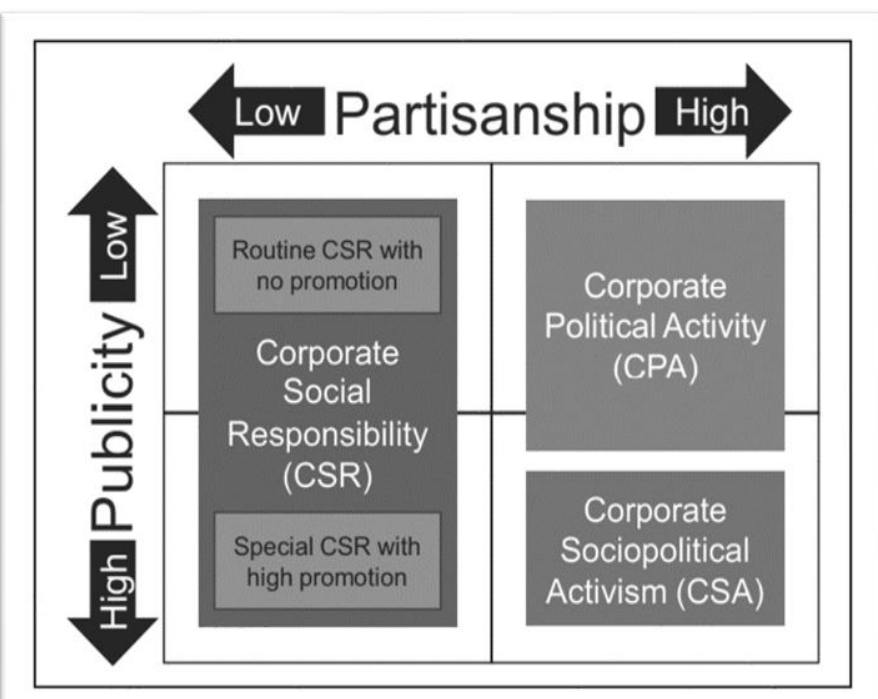

Figure I. Conceptual distinctions among CSR, CPA, and CSA.

Note. This figure is demonstrating the conceptual distinction between CSA and corporate social responsibility (CSR) and corporate political activity (CPA). Sourced from Bhagwat, Y., Warren, N. L., Beck, J. T., \& Watson, G. F., IV. (2020). Corporate Sociopolitical Activism and Firm Value. Journal of Marketing 2020, 84(5), 1-21.

doi:10.1177/00222242920937000. 
Figure 2. MANOVA Results

\begin{tabular}{lll} 
& \multicolumn{2}{c}{$\mathrm{N}$} \\
\hline CSA & 0 & 140 \\
\cline { 2 - 3 } & 1 & 147 \\
\hline \multirow{2}{*}{ PSU } & 0 & 154 \\
\cline { 2 - 3 } & 1 & 133 \\
\hline
\end{tabular}

\section{Tests of Between-Subjects Effects}

\begin{tabular}{|c|c|c|c|c|c|c|}
\hline Source & Dependent Variable & $\begin{array}{l}\text { Type III Sum } \\
\text { of Squares }\end{array}$ & $\mathrm{df}$ & $\begin{array}{l}\text { Mean } \\
\text { Square } \\
\end{array}$ & $\mathrm{F}$ & Sig. \\
\hline \multirow[t]{4}{*}{ Corrected Model } & Likelihood to support & $148.995^{\mathrm{a}}$ & 6 & 24.832 & 5.398 & .000 \\
\hline & Support with my time & $190.332^{b}$ & 6 & 31.722 & 6.154 & .000 \\
\hline & Support with my money & $106.499^{c}$ & 6 & 17.750 & 4.063 & .001 \\
\hline & Likelihood to partner & $139.369^{d}$ & 6 & 23.228 & 5.024 & .000 \\
\hline \multirow[t]{4}{*}{ Intercept } & Likelihood to support & 570.046 & 1 & 570.046 & 123.926 & .000 \\
\hline & Support with my time & 356.509 & 1 & 356.509 & 69.158 & .000 \\
\hline & Support with my money & 318.107 & 1 & 318.107 & 72.815 & .000 \\
\hline & Likelihood to partner & 383.780 & 1 & 383.780 & 83.001 & .000 \\
\hline \multirow[t]{4}{*}{ IndividualCSA1 } & Likelihood to support & 31.709 & 1 & 31.709 & 6.893 & .009 \\
\hline & Support with my time & 21.190 & 1 & 21.190 & 4.111 & .044 \\
\hline & Support with my money & 23.609 & 1 & 23.609 & 5.404 & .021 \\
\hline & Likelihood to partner & 29.516 & 1 & 29.516 & 6.384 & .012 \\
\hline \multirow[t]{4}{*}{ IndividualCSA2 } & Likelihood to support & 3.728 & 1 & 3.728 & .811 & .369 \\
\hline & Support with my time & 12.379 & 1 & 12.379 & 2.401 & .122 \\
\hline & Support with my money & 1.676 & 1 & 1.676 & .384 & .536 \\
\hline & Likelihood to partner & 5.946 & 1 & 5.946 & 1.286 & .258 \\
\hline \multirow{4}{*}{$\begin{array}{l}\text { Previous knowledge of } \\
\text { the type of organization }\end{array}$} & Likelihood to support & .854 & 1 & .854 & .186 & .667 \\
\hline & Support with my time & 9.261 & 1 & 9.261 & 1.796 & .181 \\
\hline & Support with my money & 2.542 & 1 & 2.542 & .582 & .446 \\
\hline & Likelihood to partner & 10.742 & 1 & 10.742 & 2.323 & .129 \\
\hline \multirow[t]{4}{*}{ CSA } & Likelihood to support & 24.594 & 1 & 24.594 & 5.347 & .021 \\
\hline & Support with my time & 44.017 & 1 & 44.017 & 8.539 & .004 \\
\hline & Support with my money & 6.619 & 1 & 6.619 & 1.515 & .219 \\
\hline & Likelihood to partner & $5.394 \mathrm{E}-5$ & 1 & $5.394 \mathrm{E}-5$ & .000 & .997 \\
\hline \multirow[t]{3}{*}{ PSU } & Likelihood to support & 11.802 & 1 & 11.802 & 2.566 & .110 \\
\hline & Support with my time & .009 & 1 & .009 & .002 & .966 \\
\hline & Support with my money & 3.739 & 1 & 3.739 & .856 & .356 \\
\hline
\end{tabular}




\begin{tabular}{|c|c|c|c|c|c|c|}
\hline & Likelihood to partner & 24.728 & 1 & 24.728 & 5.348 & .021 \\
\hline \multirow[t]{4}{*}{ CSA * PSU } & Likelihood to support & 6.335 & 1 & 6.335 & 1.377 & .242 \\
\hline & Support with my time & 1.839 & 1 & 1.839 & .357 & .551 \\
\hline & Support with my money & 19.345 & 1 & 19.345 & 4.428 & .036 \\
\hline & Likelihood to partner & .075 & 1 & .075 & .016 & .899 \\
\hline \multirow[t]{4}{*}{ Error } & Likelihood to support & 1287.974 & 280 & 4.600 & & \\
\hline & Support with my time & 1443.396 & 280 & 5.155 & & \\
\hline & Support with my money & 1223.243 & 280 & 4.369 & & \\
\hline & Likelihood to partner & 1294.666 & 280 & 4.624 & & \\
\hline \multirow[t]{4}{*}{ Total } & Likelihood to support & 8642.000 & 287 & & & \\
\hline & Support with my time & 7423.000 & 287 & & & \\
\hline & Support with my money & 5771.000 & 287 & & & \\
\hline & Likelihood to partner & 7616.000 & 287 & & & \\
\hline \multirow[t]{4}{*}{ Corrected Total } & Likelihood to support & 1436.969 & 286 & & & \\
\hline & Support with my time & 1633.728 & 286 & & & \\
\hline & Support with my money & 1329.742 & 286 & & & \\
\hline & Likelihood to partner & 1434.035 & 286 & & & \\
\hline
\end{tabular}
a. $\mathrm{R}$ Squared $=.104$ (Adjusted R Squared $=.084$ )
b. R Squared $=.117$ (Adjusted R Squared $=.098$ )
C. R Squared $=.080$ (Adjusted R Squared $=.060$ )
d. $R$ Squared $=.097$ (Adjusted R Squared $=.078$ ) 


\begin{tabular}{|c|c|c|c|c|c|c|}
\hline \multirow[b]{3}{*}{ Dependent Variable } & \multirow[b]{3}{*}{ CSA } & \multicolumn{3}{|c|}{ CSA * PSU } & \multirow{2}{*}{\multicolumn{2}{|c|}{ 95\% Confidence Interval }} \\
\hline & & & & & & \\
\hline & & PSU & Mean & Std. Error & Lower Bound & Upper Bound \\
\hline \multirow[t]{4}{*}{ Likelihood to support } & \multirow[t]{2}{*}{0} & 0 & $4.737^{a}$ & .255 & 4.235 & 5.239 \\
\hline & & 1 & $4.630^{\mathrm{a}}$ & .263 & 4.112 & 5.148 \\
\hline & \multirow[t]{2}{*}{1} & 0 & $5.638^{a}$ & .241 & 5.163 & 6.112 \\
\hline & & 1 & $4.929^{a}$ & .264 & 4.409 & 5.450 \\
\hline \multirow[t]{4}{*}{ Support with my time } & \multirow[t]{2}{*}{0} & 0 & $4.002^{\mathrm{a}}$ & .270 & 3.470 & 4.534 \\
\hline & & 1 & $4.152^{\mathrm{a}}$ & .279 & 3.604 & 4.701 \\
\hline & \multirow[t]{2}{*}{1} & 0 & $4.967^{\mathrm{a}}$ & .255 & 4.465 & 5.469 \\
\hline & & 1 & $4.793^{a}$ & .280 & 4.242 & 5.344 \\
\hline \multirow[t]{4}{*}{ Support with my money } & \multirow[t]{2}{*}{0} & 0 & $3.610^{\mathrm{a}}$ & .249 & 3.120 & 4.099 \\
\hline & & 1 & $3.906^{\mathrm{a}}$ & .256 & 3.401 & 4.410 \\
\hline & \multirow[t]{2}{*}{1} & 0 & $4.447^{\mathrm{a}}$ & .235 & 3.984 & 4.909 \\
\hline & & 1 & $3.691^{a}$ & .258 & 3.184 & 4.199 \\
\hline \multirow[t]{4}{*}{ Likelihood to partner } & \multirow[t]{2}{*}{0} & 0 & $4.898^{\mathrm{a}}$ & .256 & 4.395 & 5.402 \\
\hline & & 1 & $4.341^{a}$ & .264 & 3.821 & 4.860 \\
\hline & \multirow[t]{2}{*}{1} & 0 & $4.930^{\mathrm{a}}$ & .242 & 4.454 & 5.406 \\
\hline & & 1 & $4.307^{a}$ & .265 & 3.785 & 4.829 \\
\hline
\end{tabular}

a. Covariates appearing in the model are evaluated the following values: IndividualCSA1 $=3.0993$, IndividualCSA2 $=2.3554$, Previous knowledge of the type of organization described earlier $=2.34$. 
Figure 3. Positive Main Effect of CSA on Likelihood to Support

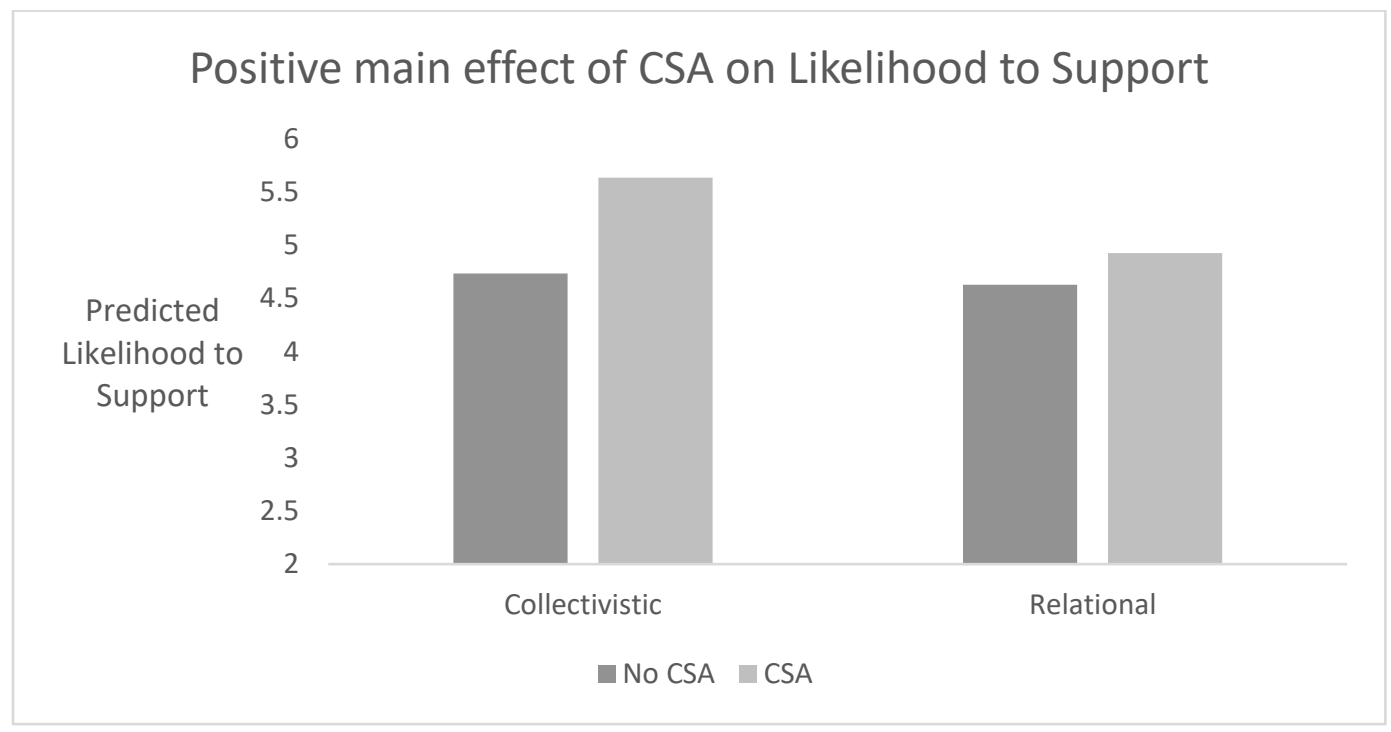


Figure 4. Positive Main Effect of CSA on Likelihood to Support with Time Positive main effect of CSA on Likelihood to Support with Time

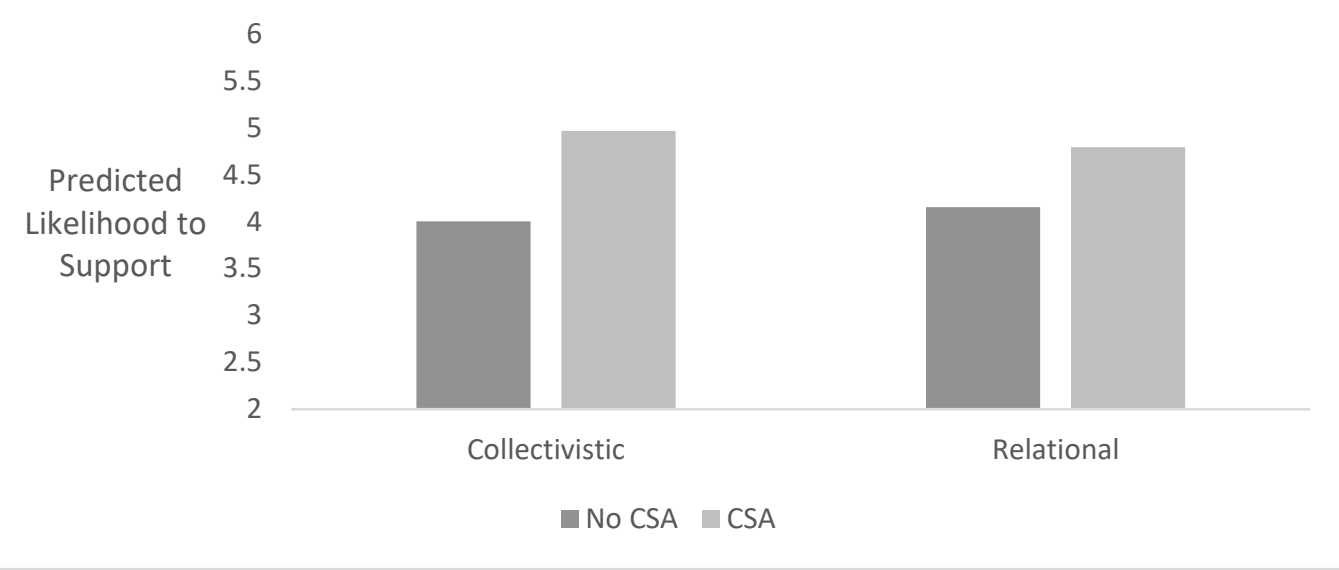


Figure 5. Positive Main Effect of CSA on Likelihood to Support with Money

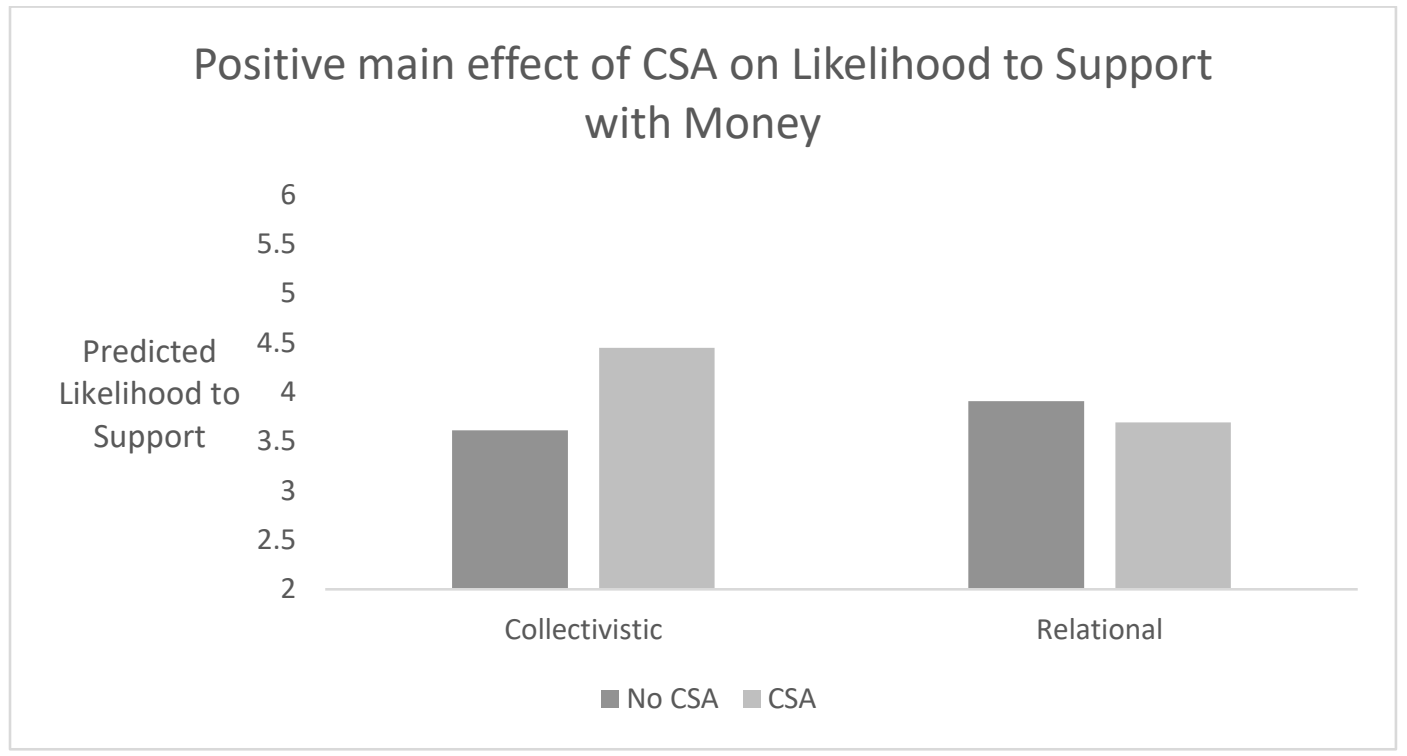


Figure 6. Positive Main Effect of Collectivistic Identity Orientation Nonprofit to Partner with For-Profit Organization

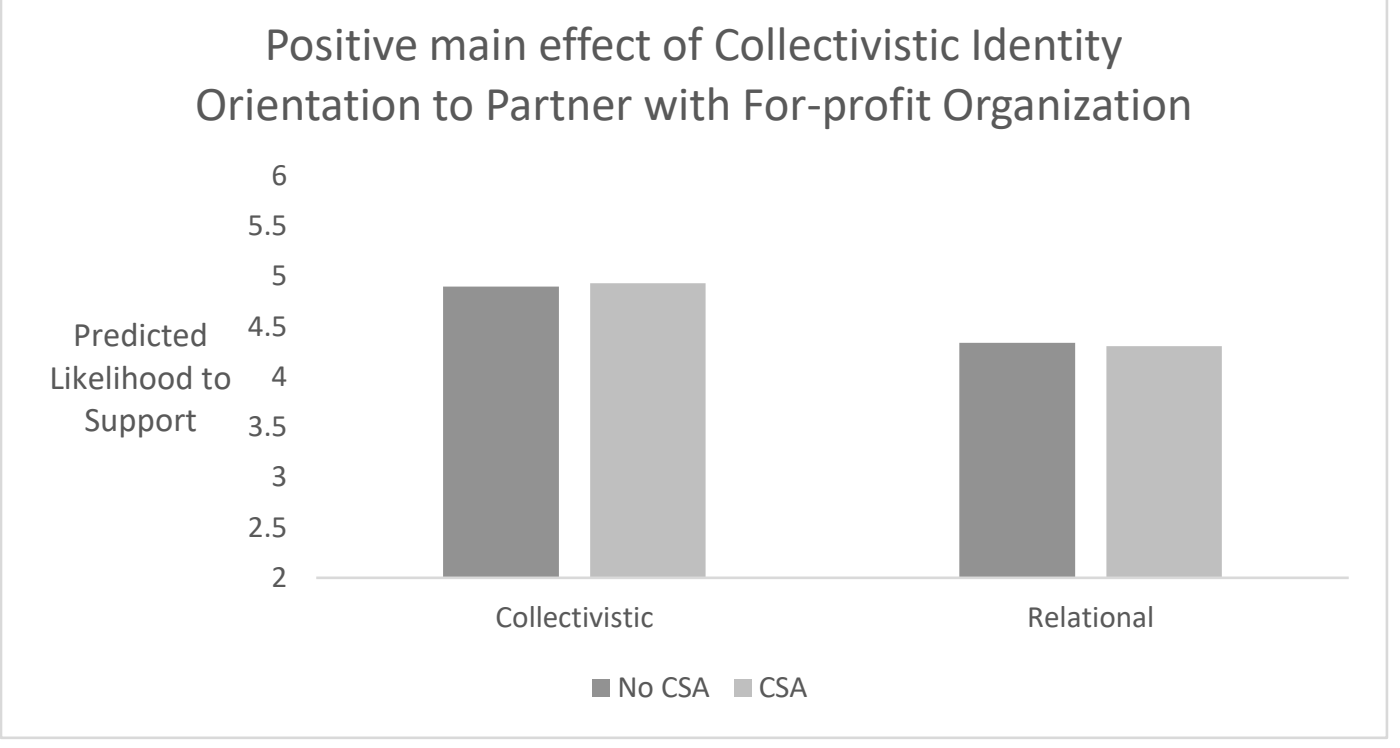


Appendix A - CSA for Nonprofits Survey

CSA for Nonprofits - Survey Base

Start of Block: Intro

Q264 Please read the information below and then click >> at the bottom of the page to begin the survey.

Q80

Project Description The purpose of this research is to explore how consumers respond to Corporate Sociopolitical Activism (DECIDES TO UTILIZE and DECIDES NOT TO UTILIZE) and Nonprofit Identity Orientation (Relational/Collectivistic). Your participation will involve responding to a series of questions about this topic. There are also questions about some personal characteristics and demographics.

Benefits and Risks of the Study You will receive no direct benefits from participating in this research study. There are minimal risks involved with participation in this project.

Principal Investigator The principal investigator is Jacob Suher. Should you have any questions or concerns please contact Jacob Suher at 503-725-9875 or at jsuher@pdx.edu.

Voluntary Participation Your participation in this project is voluntary and you are free to withdraw your consent and discontinue participation in the project at any time without penalty.

Confidentiality of Records The survey will not collect personally identifiable information, hence you will remain anonymous. The results of the study will be reported only in an aggregate form.

Participant's Rights Information If you have questions regarding your rights as a research participant, you may call the PSU Office for Research Integrity at (503) 725-2227 or 1(877) 4804400. For more information, you may also access the website at https://sites.google.com/a/pdx.edu/research/integrity.

Participant's Consent The study has been described to me and I understand that my participation is voluntary and that I am free to withdraw my consent and discontinue my participation in the project at any time without penalty. I also understand that the results of the study will be treated in strict confidence and reported only in a group form. I understand that if I have any questions or concerns about this experiment, I may pose them to Jacob Suher at 503725-9875 or at jsuher@pdx.edu. I have read and understand the above information and by 
completing this survey I attest that I am over 18 years of age and that I consent to participate in this study.

Page Break 
Q346 Timing

First Click (1)

Last Click (2)

Page Submit (3)

Click Count (4)

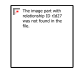

Q82

Corporate Sociopolitical Activism Survey

The following page will ask you to read about an organization's corporate sociopolitical activism (CSA) actions and answer questions about the organization. Please make sure to read all information carefully.

Corporate sociopolitical activism (CSA) is defined as a firm's public demonstration of support for or opposition to one side of a partisan sociopolitical issue. For example, an organization taking a stance on sociopolitical issues like police abolition or refugee rights. This can look like hiring refugees or implementing institutional changes that disarm police.

While there are no right or wrong answers, reading each question is required to complete this survey.

Click $>$ to begin.

\section{End of Block: Intro}

Start of Block: Scenario

Q856 Timing

First Click (1)

Last Click (2)

Page Submit (3)

Click Count (4) 
Q857 Please carefully read the information below before continuing to the next page.

\section{Display This Question:}

\section{If CSA $=1$}

And PSU $=1$

Q193 Please imagine that a local organization that has a "relational orientation" decides to engage in corporate sociopolitical activism (CSA).

A relational-oriented organization perceives themselves as relationship partners and are motivated to engage in activities that provide a benefit to others. For example, this type of organization focuses on facilitating conversation between members of the community. We want you to imagine that this organization DECIDES TO UTILIZE CSA by creating a campaign to collect signatures with a call to action requesting to defund the local police force. This is a step towards police abolition. This organization is responding to requests made by its internal and external stakeholders.

\section{Display This Question:}

\section{If $C S A=0$}

And PSU $=1$

Q325 Please imagine that a local organization that has a "relational orientation" decides NOT to engage in corporate sociopolitical activism (CSA).

A relational-oriented organization perceives themselves as relationship partners and are motivated to engage in activities that provide a benefit to others. For example, this type of organization focuses on facilitating conversation between members of the community. We want you to imagine that this organization DECIDES NOT TO UTILIZE CSA by remaining inactive when asked to create a campaign to collect signatures with a call to action requesting to defund the local police force. This would have been a step towards police abolition. This organization decides NOT to respond to requests made by its internal and external stakeholders. 
Q326 Please imagine that a local organization that has a "collectivistic orientation" decides to engage in corporate sociopolitical activism (CSA).

A collectivistic-oriented organization perceives themselves members of larger groups or communities and are thus likely to participate in activities focusing on greater collective welfare. For example, this type of organization focuses on taking actions to benefit those without power in the community.

We want you to imagine that this organization DECIDES TO UTILIZE CSA by creating a campaign to collect signatures with a call to action requesting to defund the local police force. This is a step towards police abolition. This organization is responding to requests made by its community of regular activists.

\section{Display This Question:}

If $C S A=0$

And PSU $=0$

Q327 Please imagine that a local organization that has a "collectivistic orientation" decides NOT to engage in corporate sociopolitical activism (CSA).

A collectivistic-oriented organization perceives themselves members of larger groups or communities and are thus likely to participate in activities focusing on greater collective welfare. For example, this type of organization focuses on taking actions to benefit those without power in the community.

We want you to imagine that this organization DECIDES NOT TO UTILIZE CSA by remaining inactive when asked to create a campaign to collect signatures with a call to action requesting to defund the local police force. This would have been a step towards police abolition. This organization decides NOT to respond to requests made by its community of regular activists. 
Q1034 Timing

First Click (1)

Last Click (2)

Page Submit (3)

Click Count (4)

Q1035 Please answer the question(s) below based on the information on this page.

\section{Display This Question:}

If $\operatorname{CSA}=1$

And PSU $=1$

Q29 Please imagine that a local organization that has a "relational orientation" decides to engage in corporate sociopolitical activism (CSA).

A relational-oriented organization perceives themselves as relationship partners and are motivated to engage in activities that provide a benefit to others. For example, this type of organization focuses on facilitating conversation between members of the community. We want you to imagine that this organization DECIDES TO UTILIZE CSA by creating a campaign to collect signatures with a call to action requesting to defund the local police force. This is a step towards police abolition. This organization is responding to requests made by its internal and external stakeholders.

\section{Display This Question:}

\section{If $C S A=0$}

And $P S U=1$

Q30 Please imagine that a local organization that has a "relational orientation" decides NOT to engage in corporate sociopolitical activism (CSA).

A relational-oriented organization perceives themselves as relationship partners and are motivated to engage in activities that provide a benefit to others. For example, this type of organization focuses on facilitating conversation between members of the community. We want you to imagine that this organization DECIDES NOT TO UTILIZE CSA by remaining inactive when asked to create a campaign to collect signatures with a call to action requesting to 
defund the local police force. This would have been a step towards police abolition. This organization decides NOT to respond to requests made by its internal and external stakeholders.

\section{Display This Question:}

\section{If $\operatorname{CSA}=1$}

And PSU $=0$

Q31 Please imagine that a local organization that has a "collectivistic orientation" decides to engage in corporate sociopolitical activism (CSA).

A collectivistic-oriented organization perceives themselves members of larger groups or communities and are thus likely to participate in activities focusing on greater collective welfare. For example, this type of organization focuses on taking actions to benefit those without power in the community.

We want you to imagine that this organization DECIDES TO UTILIZE CSA by creating a campaign to collect signatures with a call to action requesting to defund the local police force. This is a step towards police abolition. This organization is responding to requests made by its community of regular activists.

\section{Display This Question:}

\section{If $\operatorname{CSA}=0$}

And PSU $=0$

Q32 Please imagine that a local organization that has a "collectivistic orientation" decides NOT to engage in corporate sociopolitical activism (CSA).

A collectivistic-oriented organization perceives themselves members of larger groups or communities and are thus likely to participate in activities focusing on greater collective welfare. For example, this type of organization focuses on taking actions to benefit those without power in the community.

We want you to imagine that this organization DECIDES NOT TO UTILIZE CSA by remaining inactive when asked to create a campaign to collect signatures with a call to action requesting to 
defund the local police force. This would have been a step towards police abolition. This organization decides NOT to respond to requests made by its community of regular activists.

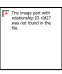

Q1040

Do you believe the organization in this example is more collectivistic or relational?

Definitely more Collectivist 1

$2(2)$

$3(3)$

$4(4)$

Equally Collectivist and Relational5 (5)

$6(6)$

7 (7)

$8(8)$

Definitely more Relational9 (9) 
Q336

Q336 Please indicate your agreement with the statements below.

$\begin{array}{ccccccccc}\begin{array}{c}\text { Strongly } \\ \text { disagree } \\ 1(1)\end{array} & 2(2) & 3(3) & 4(4) & \begin{array}{c}\text { Neither } \\ \text { agree or } \\ \text { disagree } \\ 5(5)\end{array} & 6(6) & 7(7) & 8(8) & \begin{array}{c}\text { Strongly } \\ \text { agree } \\ 9(9)\end{array}\end{array}$

The

organization

in this

example is a

collectivistic

organization.

(1)

The

organization

in this

example is a

relational

organization.

(2)

\section{End of Block: Manipulation Check}

\section{Start of Block: Support}

Q1042 Timing

First Click (1)

Last Click (2)

Page Submit (3)

Click Count (4)

Q1043 Please answer the question(s) below based on the information on this page. 
Q33 Please imagine that a local organization that has a "relational orientation" decides to engage in corporate sociopolitical activism (CSA).

A relational-oriented organization perceives themselves as relationship partners and are motivated to engage in activities that provide a benefit to others. For example, this type of organization focuses on facilitating conversation between members of the community.

We want you to imagine that this organization DECIDES TO UTILIZE CSA by creating a campaign to collect signatures with a call to action requesting to defund the local police force. This is a step towards police abolition. This organization is responding to requests made by its internal and external stakeholders.

\section{Display This Question:}

If CSA = 0

And $P S U=1$

Q34 Please imagine that a local organization that has a "relational orientation" decides NOT to engage in corporate sociopolitical activism (CSA).

A relational-oriented organization perceives themselves as relationship partners and are motivated to engage in activities that provide a benefit to others. For example, this type of organization focuses on facilitating conversation between members of the community. We want you to imagine that this organization DECIDES NOT TO UTILIZE CSA by remaining inactive when asked to create a campaign to collect signatures with a call to action requesting to defund the local police force. This would have been a step towards police abolition. This organization decides NOT to respond to requests made by its internal and external stakeholders.

\section{Display This Question:}

If CSA = 1

And PSU $=0$

Q35 Please imagine that a local organization that has a "collectivistic orientation" decides to engage in corporate sociopolitical activism (CSA). 
A collectivistic-oriented organization perceives themselves members of larger groups or communities and are thus likely to participate in activities focusing on greater collective welfare. For example, this type of organization focuses on taking actions to benefit those without power in the community.

We want you to imagine that this organization DECIDES TO UTILIZE CSA by creating a campaign to collect signatures with a call to action requesting to defund the local police force. This is a step towards police abolition. This organization is responding to requests made by its community of regular activists.

\section{Display This Question:}

If $C S A=0$

And PSU $=0$

Q36 Please imagine that a local organization that has a "collectivistic orientation" decides NOT to engage in corporate sociopolitical activism (CSA).

A collectivistic-oriented organization perceives themselves members of larger groups or communities and are thus likely to participate in activities focusing on greater collective welfare. For example, this type of organization focuses on taking actions to benefit those without power in the community.

We want you to imagine that this organization DECIDES NOT TO UTILIZE CSA by remaining inactive when asked to create a campaign to collect signatures with a call to action requesting to defund the local police force. This would have been a step towards police abolition. This organization decides NOT to respond to requests made by its community of regular activists. 
Q1048

How likely would you be to support the organization described in this example?

\section{Extremely unlikely1 (1)}

2 (2)

$3(3)$

$4(4)$

$5(5)$

$6(6)$

$7(7)$

$8(8)$

Extremely likely9 (9) 
Q1049 Please indicate your agreement with the statements below.

\begin{tabular}{|c|c|c|c|c|c|c|c|c|c|}
\hline & $\begin{array}{c}\text { Strongly } \\
\text { disagree } \\
1(1)\end{array}$ & $2(2)$ & $3(3)$ & $4(4)$ & $\begin{array}{c}\text { Neither } \\
\text { agree or } \\
\text { disagree } \\
5(5)\end{array}$ & $6(6)$ & $7(7)$ & $8(8)$ & $\begin{array}{c}\text { Strongly } \\
\text { agree } \\
9(9)\end{array}$ \\
\hline $\begin{array}{l}\text { I would like } \\
\text { to support } \\
\text { this } \\
\text { organization } \\
\text { with my } \\
\text { time. (1) }\end{array}$ & & & & & & & & & \\
\hline $\begin{array}{l}\text { I would like } \\
\text { to support } \\
\text { this } \\
\text { organization } \\
\text { with my } \\
\text { money. (2) }\end{array}$ & 7 & & & & & & & & \\
\hline
\end{tabular}

Q1052 Timing

First Click (1)

Last Click (2)

Page Submit (3)

Click Count (4)

\section{Display This Question:}

If $\operatorname{CSA}=1$

And PSU $=1$

Q37 Please imagine that a local organization that has a "relational orientation" decides to engage in corporate sociopolitical activism (CSA).

A relational-oriented organization perceives themselves as relationship partners and are 
motivated to engage in activities that provide a benefit to others. For example, this type of organization focuses on facilitating conversation between members of the community. We want you to imagine that this organization DECIDES TO UTILIZE CSA by creating a campaign to collect signatures with a call to action requesting to defund the local police force. This is a step towards police abolition. This organization is responding to requests made by its internal and external stakeholders.

\section{Display This Question:}

If CSA $=0$

And PSU $=1$

Q38 Please imagine that a local organization that has a "relational orientation" decides NOT to engage in corporate sociopolitical activism (CSA).

A relational-oriented organization perceives themselves as relationship partners and are motivated to engage in activities that provide a benefit to others. For example, this type of organization focuses on facilitating conversation between members of the community. We want you to imagine that this organization DECIDES NOT TO UTILIZE CSA by remaining inactive when asked to create a campaign to collect signatures with a call to action requesting to defund the local police force. This would have been a step towards police abolition. This organization decides NOT to respond to requests made by its internal and external stakeholders.

\section{Display This Question:}

\section{If $\operatorname{CSA}=1$}

And PSU $=0$

Q39 Please imagine that a local organization that has a "collectivistic orientation" decides to engage in corporate sociopolitical activism (CSA).

A collectivistic-oriented organization perceives themselves members of larger groups or communities and are thus likely to participate in activities focusing on greater collective welfare. For example, this type of organization focuses on taking actions to benefit those without power in the community.

We want you to imagine that this organization DECIDES TO UTILIZE CSA by creating a campaign to collect signatures with a call to action requesting to defund the local police force. 
This is a step towards police abolition. This organization is responding to requests made by its community of regular activists.

\section{Display This Question:}

If $C S A=0$

And PSU $=0$

Q40 Please imagine that a local organization that has a "collectivistic orientation" decides NOT to engage in corporate sociopolitical activism (CSA).

A collectivistic-oriented organization perceives themselves members of larger groups or communities and are thus likely to participate in activities focusing on greater collective welfare. For example, this type of organization focuses on taking actions to benefit those without power in the community.

We want you to imagine that this organization DECIDES NOT TO UTILIZE CSA by remaining inactive when asked to create a campaign to collect signatures with a call to action requesting to defund the local police force. This would have been a step towards police abolition. This organization decides NOT to respond to requests made by its community of regular activists.

Q1053 Please answer the question(s) below based on the information on this page.

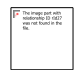


Q1054

Imagine you are running an organization (for-profit), how likely would you be to partner with the organization described in this example?

\section{Extremely unlikely1 (1)}

$2(2)$

3 (3)

4 (4)

$5(5)$

$6(6)$

7 (7)

$8(8)$

Extremely likely9 (9)

Q250 We now have a few general questions about your actual behaviors and characteristics. Remember that there are no right or wrong answers and your responses are anonymous. 
Q294 Please rate your previous knowledge of the type of organization described earlier, compared to the rest of the population?

\begin{tabular}{c|ccccc|c|} 
& $1(1)$ & $2(2)$ & $3(3)$ & $4(4)$ & $5(5)$ & $\begin{array}{c}\text { High } \\
\text { previous } \\
\begin{array}{c}\text { Low } \\
\text { previous } \\
\text { knowledge }\end{array}\end{array}$ \\
knowledge
\end{tabular}


Page Break 
2

Q256 Please indicate how likely is it that you will engage in the activities described below in the future. 
Extremely

unlikely

1 (1)

$2(2)$

$3(3)$

4 (4)

$5(5)$

$6(6)$

Extremely

Invite a friend

to attend a

meeting of a political

organization

or event? (1)

Purchase a

poster, t-

shirt, etc.

that endorses

a political

point of

view? (2)

Donate

money to a

political

candidate or

organization?

(13)

Attend a

political

organization's

regular

planning

meeting? (14)

Block access

to a building

or public area with your

body? (16)

Engage in a political

activity in

which you

feared for

your personal

safety? (17) 
Engage in
sociopolitical
activity for
police
abolition?

(19)

\section{End of Block: Individual Differences}

\section{Start of Block: Exit}

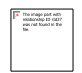

Q28 (optional) Do you have any comments or questions about this survey? Please feel free to enter below.

Q324 Click >> to complete the survey, thank you! 